\title{
Impact of tropical forest logging on the reproductive success of leatherback turtles
}

Article in Marine Ecology Progress Series · April 2017

DOI: $10.3354 /$ meps12064

CITATIONS

0

4 authors, including:

Juan Patino-Martinez

Estación Biológica de Doñana

19 PUBLICATIONS 140 CITATIONS

SEE PROFILE

Adolfo Marco

Estación Biológica de Doñana

158 PUBLICATIONS 2,492 CITATIONS

SEE PROFILE
Brendan John Godley

University of Exeter

365 PUBLICATIONS 11,005 CITATIONS

SEE PROFILE

Some of the authors of this publication are also working on these related projects: 


\title{
Impact of tropical forest logging on the reproductive success of leatherback turtles
}

\author{
Juan Patino-Martinez ${ }^{1,2}$, Brendan J. Godley ${ }^{2}$, Liliana Quiñones ${ }^{1}$, Adolfo Marco ${ }^{1, *}$ \\ ${ }^{1}$ Doñana Biological Station, CSIC, Department for Biodiversity Conservation, Av. AméricoVespucio s/n, 41092 Seville, Spain \\ ${ }^{2}$ Marine Turtle Research Group, Centre for Ecology and Conservation, University of Exeter, Cornwall Campus, UK
}

\begin{abstract}
Logging in tropical forests causes, among other impacts, the accumulation of organic debris on many beaches after it is carried to the coast by rivers and concentrated by oceanographic processes. Such accumulated beach organic material (ABOM) has the potential to exert important negative effects on the reproductive success of marine turtles. Females must be able to exit the ocean and cross sandy beaches to nest and, as no parental care is provided, hatchlings must cross the beach to reach the sea following emergence from the nest. We investigated how ABOM affects nest site selection and hatchling dispersal at a globally important rookery for leatherback turtles Dermochelys coriacea in Colombia. Detailed surveys were combined with field experiments in which the amount of ABOM was manipulated. Areas with higher ABOM had a similar rate of nesting, but females spent significantly more time in nest camouflage, suffered external lesions and nested closer to the shoreline, increasing the risk of egg mortality caused by flooding and erosion. When ABOM was manually removed from several beach sectors, nest site selection moved towards areas with less risk of flooding or tidal erosion. In nesting seasons with higher ABOM, a lower rate of female recapture was experienced, suggesting a greater dispersion of nests, possibly emigration. ABOM represents a barrier for many hatchlings, causing them to spend significantly more time reaching the sea, thereby increasing their energy output and their risk of predation or desiccation.
\end{abstract}

KEY WORDS: Conservation · Pollution $\cdot$ Sea turtle $\cdot$ Behaviour $\cdot$ Deforestation $\cdot$ Driftwood $\cdot$ Debris $\cdot$ Dermochelys coriacea $\cdot$ Nesting

Resale or republication not permitted without written consent of the publisher

\section{INTRODUCTION}

Tropical forest logging can have severe negative impacts on biodiversity (Foley et al. 2007). Following inefficient logging practices, forest debris transported in storm runoff through rivers to the sea can cause collateral impacts across multiple ecosystems (Putz et al. 2000). Such issues are clearly illustrated along coastlines, and in particular sandy beaches where debris arrives from the sea forming parallel barriers on the shoreline (Velander \& Mocogni 1999). Sandy beaches are obligate nesting areas for sea turtles (Thiel \& Gutow 2005), and it is somewhat intuitive that this kind of debris may affect both adult and hatchling marine turtles. However, few studies have quantified the impact caused by accumulated beach debris on sea turtle reproduction, although, for example, in Gabon forest-related debris is extensively distributed (Pikesley et al. 2013), and nesting females have been known to die as a result of being trapped by large logs washed up on beaches (Laurance et al. 2008).

In addition to adult survival, debris has the potential to impact nesting behaviour (including nest site selection) as well as nest success factors. Many biotic (Phillott et al. 2002, Phillott \& Elsmore 2004, PatinoMartinez et al. 2012a, Sarmiento-Ramírez et al. 2014, Brost et al. 2015) and abiotic (Patino-Martinez et al. 2012b, 2014, Rivas et al. 2016, Marco et al. 2017) factors of the nest environment can affect embryonic 
development and hence reproductive success (Wallace et al. 2004, Houghton et al. 2007, Pike \& Stiner 2007, Lolavar \& Wyneken 2015). Nest success depends on a diverse array of factors such as moisture (Patino-Martinez et al. 2014), oxygen or salt content (Ackerman 1980), temperature (Godley et al. 2002, Matsuzawa et al. 2002, Reece et al. 2002, Patino-Martinez et al. 2012b, Howard et al. 2014), and sand texture and density (Mortimer 1990, Wood \& Bjorndal 2000, Antworth et al. 2006). The position of the nest between the sea and the backing vegetation has the potential to affect environmental conditions that influence nest success or neonate survival (Hays \& Speakman 1993). For instance, numerous leatherback nests fail in areas susceptible to flooding by tides or erosion, with losses, in some cases, of more than $50 \%$ of nests (Whitmore \& Dutton 1985, Bilinski et al. 2001, Bell et al. 2004, Hernandez et al. 2007). Likewise, invasion of the nest by roots or hatchling disorientation can occur amongst vegetation (Godfrey \& Barreto 1995, Kamel \& Mrosovsky 2004, Rivas \& Marco 2016). Selection of a suitable site for nest positioning is conditioned, in all likelihood, by beach features, such as slope, erosion, beach dimensions, sand quality, tidal condition or presence of obstacles that may hinder the mobility of reproductive females (Wood \& Bjorndal 2000, Laurance et al. 2008).

After hatching, the transit of hatchlings from the nest to the sea is a process subject to risks that can significantly affect turtle survival. When hatchlings emerge from the nest, generally between dusk and dawn (Glen et al. 2005), they immediately dash towards the sea. Orientation is determined by visual stimuli, which lures them to the bright reflection of the ocean (Godfrey \& Barreto 1995, Bourgeois et al. 2009), as well as being influenced by slope (Salmon et al. 1992, Salmon \& Witherington 1995). Throughout this journey from the bottom of the nest to the water, hatchlings are exposed to an array of predators (Engeman et al. 2003, 2005, Maros et al. 2005). Predation rates may vary according to nest location and time invested prior to reaching the sea (Kamel \& Mrosovsky 2004). Minimising the duration to cover this distance is vital for hatchling survival for 2 reasons: firstly, to make the most out of the energetic reserves during the first hours of swimming frenzy in surface waters, where predators thrive (Wyneken \& Salmon 1992); secondly, to minimise hazards such as predation, exhaustion and dehydration on the beach (Bourgeois et al. 2009). Offspring hatching from nests amongst vegetation may invest more time transiting the beach, increasing their vulnerability to predation on land (Godfrey \& Barreto 1995) or in predator-rich inshore waters (Reising et al. 2015).

The aim of this study was to assess the effect of accumulated beach organic material (ABOM) on leatherback turtles Dermochelys coriacea in 3 main ways: (1) Is nest site selection relative to tideline and beach vegetation affected, and what are the implications for egg survival? (2) Are there any effects on female nesting behaviour (beach selection, nest construction, egg laying and nest camouflaging)? (3) Are there any impacts on sea-finding behaviour in hatchlings?

\section{MATERIALS AND METHODS}

This study was carried out at Playona, in the western Colombian Caribbean $\left(8.459^{\circ} \mathrm{N}, 77.226^{\circ} \mathrm{W}\right)$ during the nesting seasons of 2005, 2006 and 2007. This is a high-density nesting site that is subject to a high level of negative impacts, such as egg harvesting, nest flooding and extensive build up of $\mathrm{ABOM}$ (Patino-Martinez et al. 2008). We focused on a $3 \mathrm{~km}$ section at the north end of the site due to its higher nest density ( $>81$ nests $\mathrm{km}^{-1}$ ) (Patino-Martinez et al. 2008). The amount of ABOM on the beach throughout the study varied in time and space, apparently determined by tidal and wave action and by prevailing weather conditions. The highest amounts of debris accumulation took place after rains, which increased river flow and seaward transport of ABOM.

\section{Field survey 1: nesting activity}

Field surveys suggested that we could establish a classification of 3 degrees of ABOM: (1) absent: lacking any noticeable $\mathrm{ABOM}_{i}(2)$ intermediate: $\mathrm{ABOM}$ $\leq 1 \mathrm{~m}^{2}$ coverage per linear metre of beach, with debris of diameter $\leq 20 \mathrm{~cm}$ and length $\leq 3 \mathrm{~m}$; and (3) high: $\mathrm{ABOM}>1 \mathrm{~m}^{2}$ coverage per linear metre of beach with debris diameter $>20 \mathrm{~cm}$ or length $>3 \mathrm{~m}$. For 67 nights (12 March to 18 May 2007), the beach was monitored for nesting females and nesting behaviour. At least 2 experienced observers were assigned to each kilometre of beach, with continuous patrolling from 20:00 to 03:00 h each night. When a female was intercepted emerging from the sea, the degree of $\mathrm{ABOM}$ was assigned to the $20 \mathrm{~m}$ beach section centred on the emergence point, and the duration of the following behaviours was recorded: nest site selection (from the moment that females passed the high tide line until they began digging the 
nest chamber), egg laying, nest camouflaging and descent to the sea (from the end of nest camouflaging until they passed the high tide line toward the water). Moreover, for each studied female, the following variables were recorded: curved carapace length and width (CCL and CCW, respectively), nest depth (measured with a rigid tape measure immediately before the beginning of egg laying), clutch size (eggs were counted during oviposition) and distance to the tideline and to the vegetation line. All nests were assigned to 1 of 3 longitudinal sections of the beach in the following manner: (1) wash zone: comprising the area below the high tideline; (2) intermediate zone: encompassing the area of open sand between the tideline and the vegetation line; and (3) vegetation zone: covered by vegetation (Patino-Martinez et al. 2008). This categorization allowed designating of the different forms and degrees of threat to nest viability (Nordmoe et al. 2004). In this manner, nests unmistakably located within the wash zone were considered at risk from inundation or erosion (PatinoMartinez et al. 2008). Any incident taking place during the nesting process, such as flooding or abandonment of the nest, wounds incurred by interaction with debris or evidence of former lesions were also recorded. Each turtle intercepted was identified with 2 standard Monel-49 tags attached to the caudal aspect of the proximate part of the hind fins.

\section{Field survey 2: inter-nesting behaviour}

To evaluate the effect of ABOM encountered during nesting on the probability that a female would repeat nesting on the same beach, a capture-markrecapture study was carried out during the 2005, 2006 and 2007 seasons. ABOM levels differed markedly among years (2005: the entire beach was free of debris; 2006: very high levels of ABOM that covered the whole study zone during the whole study period; 2007: intermediate amounts of ABOM throughout the study area). Females have an interval of approximately $9 \mathrm{~d}$ between successive clutches (Chacón-Chaverri 1999, Hilterman \& Goverse 2007), and thus it was possible to group the data from each year into 7 sessions of $9 \mathrm{~d}$ each, hence avoiding data repetition from a given female in the same session. Using the programme MARK (Cooch \& White 2004) and capture-recapture data from 413 females, the survival (Phi) and recapture $(\mathrm{P})$ rates (P indicates the probability that a female would repeat nesting on the same beach) were modelled in relation to the variation in the amount of $\mathrm{ABOM}$ among years (ABOM) and within each season (session), including the sum (ABOM+session) and the interaction (ABOM $\times$ session).

In the model, the estimated survival rate (Phi) is affected by both female mortality and their permanent emigration from the study area, while the recapture rate $(\mathrm{P})$ reflects both the variation in the observation/ capture effort and temporary emigration out of the study area. Quasi-likelihood Akaike's information criterion (QAICC) was used to select the best model (Anderson et al. 1994). The models with the lowest QAICc and with the fewest parameters are considered the best fit for the data. Model selection was carried out on the basis of the model with the most parameters in which both the survival and recapture probabilities varied in accordance with $\mathrm{ABOM}$ (year) and within the same season (session). The fit of the data to the Cormack-Jolly-Seber (CJS) model was evaluated using the programme Release GOF (goodness-of-fit test) (Burnham et al. 1987). This was used to test whether the probability of recapture over time was the same for all marked individuals. The goodness-offit of the model was also evaluated using a parametric approximation (bootstrapping). The parameters estimated for the model were used to simulate data according to the assumptions of the CJS models (the individuals were independent and no overdispersion of data occurred). This process was repeated 1000 times, and the deviance of each model was calculated to determine whether the deviance of the observed model exceeded the deviance of the simulated data. The overdispersion parameter (c-hat) was calculated as the ratio between the average deviance of the simulated models and the observed deviance of the model (Cooch \& White 2004). No evidence of significant overdispersion was found (c-hat $=0.92$ ) and thus there was no evidence of any deviation from the assumption that the individuals were mutually independent (Anderson et al. 1994). The results were adjusted to a c-hat of 0.92 (ideal c-hat $=1$ ), even though this adjustment had no qualitative effects on the results. Flipper tags can have a significant rate of loss (Rivalan et al. 2005). However, no females were observed as having lost any tags on the beach during the study, and thus, given double tagging, the rate of tag loss appeared not to be markedly affected by the level of ABOM on the beach.

\section{Field experiment 1: nesting behaviour}

A $300 \mathrm{~m}$ beach segment characterized by homogeneous qualities of width, sand type, ABOM and slope was chosen. Within this segment, ABOM was cleared in 50 m segments $(n=3)$ that alternated with 3 other 
sectors where ABOM was left in situ. ABOM in control sectors was cleared daily in the afternoons. The experimental sectors were surveyed every morning between 06:00 and 08:00 h (from 13 March to 14 June 2007), quantifying the following: (1) number of nesting attempts within each experimental zone; $(2)$ number of females that nested below, within or above the ABOM line; (3) number of nests located in areas at risk from intertidal flooding; and (4) number of females that left the beach without nesting. We only used nesting data that were completely carried out within each experimental zone. Some short false crawls may have been fully effaced by the nighttime high tide and not recorded during daytime surveys. Thus, nesting success could be slightly overestimated at all levels of ABOM.

\section{Field experiment 2: hatchling behaviour}

The effect of $\mathrm{ABOM}$ on hatchling movement was quantified by exposing hatchlings to different levels of $\mathrm{ABOM}$ on their way to the sea. A total of 89 hatchlings emerging just before sunset belonging to 3 different nests in a hatchery were selected and assigned to 1 of 2 experimental conditions. Thus, 42 turtles were released in areas without $\mathrm{ABOM}$ (cleared) and 47 in areas with intermediate levels of ABOM (see above). Hatchlings from each nest were proportionally distributed to each experimental condition (Nest 1: 9 hatchlings in no ABOM and 10 in $\mathrm{ABOM}_{i}$ Nest 2:

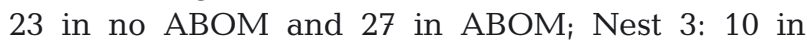
no $\mathrm{ABOM}$ and 10 in $\mathrm{ABOM}$ ). All hatchlings were released $17 \mathrm{~m}$ from the sea. For each condition, we recorded the number of hatchlings that reached the sea, and for each hatchling we also measured the duration of beach transit. Events such as becoming overturned and attacks by crabs were also quantified.

\section{RESULTS}

\section{Field survey 1: nesting activity}

In total, we identified 216 different females after $67 \mathrm{~d}$ of monitoring. During this period, a total of 287 nesting attempts (NAs) were analysed: 69 NAs in areas with $\mathrm{ABOM}$ absent, 147 NAs in areas with intermediate $\mathrm{ABOM}$ and $71 \mathrm{NAs}$ in areas with high ABOM. When we compared the 3 levels of ABOM, the proportion of NAs that resulted in successful nesting was similar $\left(\chi^{2}=0.541 ; \mathrm{df}=2 ; \mathrm{p}=0.763\right.$; $92.7 \%$ of NAs in areas without $\mathrm{ABOM}, 89.8 \%$ in areas of intermediate $\mathrm{ABOM}$ and $91.5 \%$ in areas of

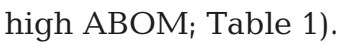

The levels of ABOM significantly affected the distance of nests to the sea. Females in zones with high $\mathrm{ABOM}$ nested closer to the tideline compared to females that nested in zones without $A B O M$ (ANOVA: $\mathrm{df}=2 ; F=3.31 ; \mathrm{p}=0.03$; Table 1, Fig. 1A). The amount of ABOM on the beach did not influence the time turtles invested in nest site selection (ANCOVA: $F_{2,26}=0.03, \mathrm{p}=0.99$; covariable $=$ adult female $\mathrm{CCL}$ ) nor the time devoted to egg laying (ANCOVA: $F_{2,74}=0.04, \mathrm{p}=0.7$ ). The mean depth of the nests was significantly lower in areas with high levels of ABOM (ANCOVA: $F_{2,139}=3.15, p=0.046$; Table 1, Fig. 1B). The amount of ABOM had a significant effect on the time dedicated to nest camouflage (ANCOVA: $F_{2,45}=4.02, \mathrm{p}=0.025$; Table 1, Fig. 1C), with turtles in high ABOM areas lengthening their nest camouflaging time by 33 to $42 \%$ over the other 2 groups (absent ABOM: $45.8 \pm 1.8$ [SE] min; intermediate ABOM: $42.8 \pm 3.8$ min.; high ABOM: $60.5 \pm$ $9.7 \mathrm{~min}$; Table 1, Fig. 1C). No female mortality was recorded as a result of ABOM. However, lesions were incurred from physical contact with $\mathrm{ABOM}$ on shoulders and flippers $(2.8 \%, \mathrm{n}=6$ females), carapace $(1.4 \%, \mathrm{n}=3)$ and head or eyes $(1.4 \%, \mathrm{n}=3)$.

\section{Field survey 2: inter-nesting behaviour}

Although the sampling effort was practically the same every year, the recapture rates $(\mathrm{P})$ were affected by the temporary dispersion of females to other beaches. Female recapture rate was higher in the ABOM-free year than in those with medium or high $\mathrm{ABOM}$ conditions (2005: no $\mathrm{ABOM}=0.41 \pm 0.04$; 2006: high $\mathrm{ABOM}=0.18 \pm 0.03 ; 2007$ : intermediate $\mathrm{ABOM}=0.27 \pm 0.04)$. When the recapture probability was modelled, the lowest QAICc value was for the model that assumed differences in the recapture rates between $\mathrm{ABOM}$ conditions ( $\mathrm{P} \mathrm{ABOM})$. The survival rate (Phi) varied in relation to the breeding season (session) and did not depend on the year. Thus, the model supported by the QAICc values was Phi (session) $\mathrm{P}(\mathrm{ABOM})$. This model was well fitted to the CJS assumptions (bootstrap goodness-of-fit test, $\mathrm{p}=0.27$ ). All models are presented in Table A1 in Appendix 1.

\section{Field experiment 1: nesting behaviour}

ABOM level did not affect the rate of NA (ANOVA: $F_{1,76}=1.235 ; \mathrm{p}=0.269$ ), nor rates of nesting success 
Table 1. Descriptive statistics of nest characteristics, female biometrics and nesting behaviour of leatherback turtles Dermochelys coriacea by level of accumulated beach organic material (ABOM). Results of ANOVAs and ANCOVAs comparing the $3 \mathrm{ABOM}$ conditions established during field surveys (absent, intermediate and high). CCL (CCW): curved carapace length (width). Significant $(\mathrm{p}<0.05)$ results are shown in bold

\begin{tabular}{|c|c|c|c|c|c|c|}
\hline & $\mathrm{ABOM}$ & $\mathrm{N}$ & Mean $\pm \mathrm{SD}(95 \% \mathrm{CI})$ & df & $F$ & $\mathrm{p}$ \\
\hline $\begin{array}{l}\text { Nest depth }(\mathrm{cm}) \text { (CCL was a } \\
\text { covariable in the analysis) }\end{array}$ & $\begin{array}{l}\text { Absent } \\
\text { Intermediate } \\
\text { High }\end{array}$ & $\begin{array}{l}45 \\
71 \\
32\end{array}$ & $\begin{array}{l}74.2 \pm 1.0(72-76) \\
75.3 \pm 0.9(74-77) \\
71.8 \pm 1.3(69-74)\end{array}$ & 2,139 & 3.15 & 0.046 \\
\hline Female CCL (cm) & $\begin{array}{l}\text { Absent } \\
\text { Intermediate } \\
\text { High }\end{array}$ & $\begin{array}{c}63 \\
136 \\
65\end{array}$ & $\begin{array}{l}149.5 \pm 0.9(148-151) \\
149.7 \pm 0.5(149-151) \\
150.8 \pm 1.0(149-153)\end{array}$ & 2,261 & 0.69 & 0.50 \\
\hline Female CCW $(\mathrm{cm})$ & $\begin{array}{l}\text { Absent } \\
\text { Intermediate } \\
\text { High }\end{array}$ & $\begin{array}{c}62 \\
136 \\
64\end{array}$ & $\begin{array}{l}110.1 \pm 0.7(109-111) \\
109.8 \pm 0.4(109-111) \\
111.0 \pm 0.7(110-112)\end{array}$ & 2,259 & 1.27 & 0.28 \\
\hline Eggs & $\begin{array}{l}\text { Absent } \\
\text { Intermediate } \\
\text { High }\end{array}$ & $\begin{array}{l}45 \\
66 \\
34\end{array}$ & $\begin{array}{l}76.8 \pm 2.9(71-83) \\
82.1 \pm 2.2(78-86) \\
80.5 \pm 3.6(73-88)\end{array}$ & 2,142 & 1.01 & 0.37 \\
\hline Shelled albumen globules & $\begin{array}{l}\text { Absent } \\
\text { Intermediate } \\
\text { High }\end{array}$ & $\begin{array}{l}43 \\
64 \\
33\end{array}$ & $\begin{array}{l}28.9 \pm 2.0(25-33) \\
31.0 \pm 1.4(28-34) \\
29.5 \pm 2.2(25-34)\end{array}$ & 2,137 & 0.42 & 0.66 \\
\hline Distance of nest to tideline (m) & $\begin{array}{l}\text { Absent } \\
\text { Intermediate } \\
\text { High }\end{array}$ & $\begin{array}{l}49 \\
88 \\
40\end{array}$ & $\begin{array}{l}15.5 \pm 1.0(14-17) \\
13.5 \pm 0.7(12-15) \\
12.0 \pm 1.0(10-14)\end{array}$ & 2,174 & 3.31 & 0.03 \\
\hline Distance of nest to vegetation (m) & $\begin{array}{l}\text { Absent } \\
\text { Intermediate } \\
\text { High }\end{array}$ & $\begin{array}{l}45 \\
81 \\
39\end{array}$ & $\begin{array}{l}5.9 \pm 0.5(5-7) \\
5.4 \pm 0.5(4-6) \\
6.5 \pm 0.7(5-8)\end{array}$ & 2,162 & 0.9 & 0.40 \\
\hline Time for nest site selection (min) & $\begin{array}{l}\text { Absent } \\
\text { Intermediate } \\
\text { High }\end{array}$ & $\begin{array}{c}23 \\
12 \\
7\end{array}$ & $\begin{array}{l}49.9 \pm 2.9(44-56) \\
52.3 \pm 2.2(48-57) \\
51.3 \pm 4.0(42-61)\end{array}$ & 2,26 & 0.03 & 0.99 \\
\hline Time for egg laying (min) & $\begin{array}{l}\text { Absent } \\
\text { Intermediate } \\
\text { High }\end{array}$ & $\begin{array}{l}41 \\
39 \\
17\end{array}$ & $\begin{array}{l}11.4 \pm 0.4(11-12) \\
10.9 \pm 0.4(10-12) \\
11.2 \pm 0.6(10-12)\end{array}$ & 2,74 & 0.04 & 0.7 \\
\hline Time for nest camouflaging (min) & $\begin{array}{l}\text { Absent } \\
\text { Intermediate } \\
\text { High }\end{array}$ & $\begin{array}{c}30 \\
13 \\
9\end{array}$ & $\begin{array}{l}45.8 \pm 1.8(42-50) \\
42.8 \pm 3.8(34-51) \\
60.5 \pm 9.7(38-83)\end{array}$ & 2,45 & 4.02 & 0.02 \\
\hline
\end{tabular}
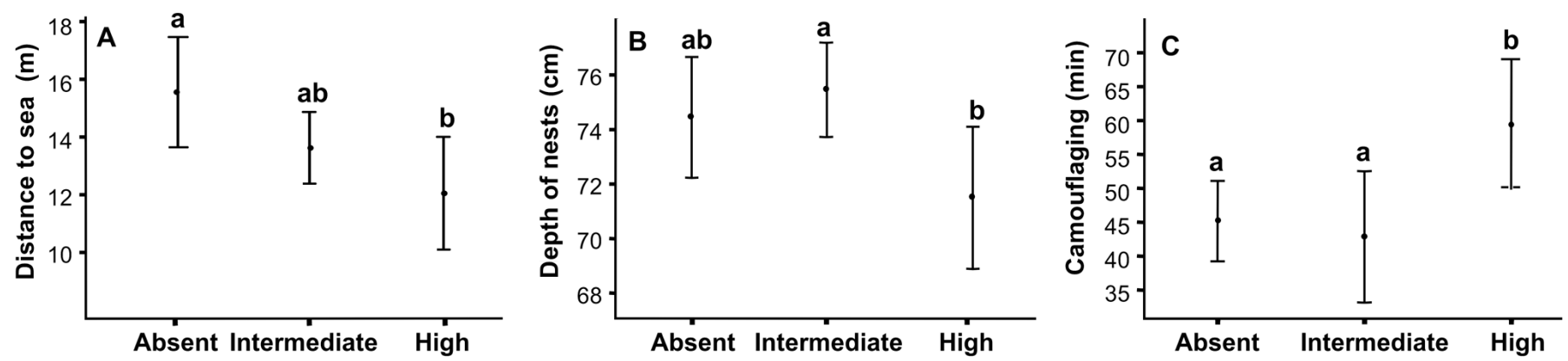

Fig. 1. Impacts on nesting behaviour of leatherback turtles Dermochelys coriacea of different accumulated beach organic material (ABOM) conditions (absent, intermediate or high). (A) Mean distance (m) of nests relative to the sea. (B) Mean depth of nests $(\mathrm{cm})$. (C) Time (min) invested by females in nest camouflaging. Bars represent mean $\pm 95 \%$ CI. Different lower-case letters indicate statistically significant differences $(\mathrm{p}<0.05)$ 
(ABOM: 2 NAs without clutch deposition out of 52 attempts [3.8\%]; ABOM-free: 2 NAs without clutch deposition out of 62 attempts $(3.2 \%)$; Pearson chisquared test, $\left.\chi^{2}=0.03, \mathrm{df}=1, \mathrm{p}=0.86\right)$. However, the proportion of turtles above the strandline during the nesting process was $62.5 \%(\mathrm{n}=35)$ in areas without $\mathrm{ABOM}$, and $20.8 \%(\mathrm{n}=10)$ in areas with $\mathrm{ABOM}$ (Fig. 2A), and this difference was statistically significant (Pearson $\chi^{2}=19.25, \mathrm{p}<0.0001$ ). The proportion of turtles that nested in areas with a high risk of flooding or erosion was significantly greater in areas with ABOM (38.5 vs. $8.9 \%$, Pearson $\chi^{2}=12.06$, p < 0.001; Fig. 2B).

\section{Field experiment 2: hatchling behaviour}

In the zone without $\mathrm{ABOM}$, the mean beach transit time was $6.2 \pm 0.2 \min (\mathrm{n}=42)$, compared to $8.2 \pm$ 0.4 min $(\mathrm{n}=47)$ in the ABOM zone (Fig. 3). These

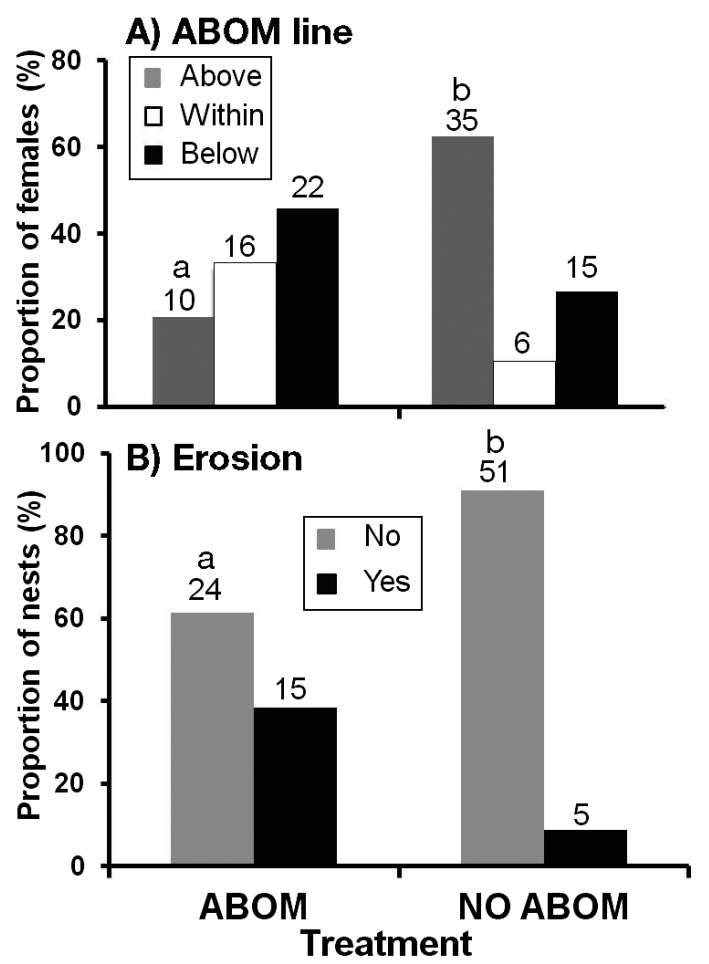

Fig. 2. Impacts of ABOM on leatherback turtle Dermochelys coriacea nesting success. (A) Proportion of females nesting in areas relative to the accumulated beach organic material $(\mathrm{ABOM})$ line: above $=$ nests laid beyond the $\mathrm{ABOM}$ line in areas with the lowest risk of flooding; within = nests laid amongst $\mathrm{ABOM}_{\text {; }}$ below = nests laid before reaching the $\mathrm{ABOM}$ line and in close proximity to the sea. (B) Percentage of nests in areas of the beach at high risk of erosion. In both panels, numbers above bars indicate absolute numbers of turtles and different lower-case letters indicate statistically significant differences $(\mathrm{p}<0.01)$

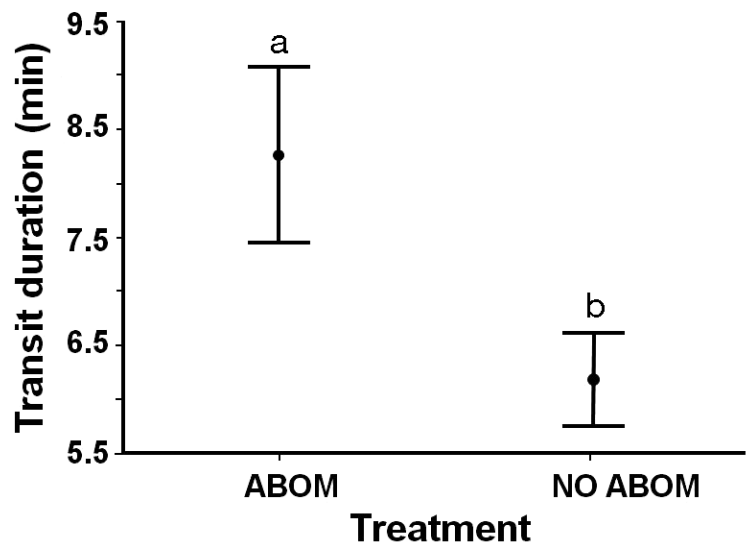

Fig. 3. Impacts of ABOM on leatherback turtle Dermochelys coriacea hatchling transit time: mean duration for hatchlings to crawl from the release point to the sea. Bars represent mean $\pm 95 \% \mathrm{CI}$ and different lower-case letters indicate statistically significant differences $(\mathrm{p}<0.01)$

differences represented an important delay in time to reach the sea for hatchlings from 2 of the 3 study clutches (Mann-Whitney $U$-test: Nest $1 ; U=13.5, \mathrm{p}<$ 0.001; Nest 2: $U=16.7, \mathrm{p}<0.001$; Nest 3: $U=1.04, \mathrm{p}=$ 0.307 ). The most frequently displayed behaviour by hatchlings when making contact with $\mathrm{ABOM}$ consisted of trying to climb over it head-on until becoming immobilized either under or on top of the waste, and then moving laterally to try and descend at another location. Despite ABOM conditions being intermediate, hatchlings turned upside-down 14 times (mean of 0.3 times hatchling ${ }^{-1}$ ) compared to control conditions under which they only turned upside-down 3 times (mean of 0.07 times hatchling $\left.{ }^{-1}\right)$. Attacks by crabs were infrequent $(\mathrm{n}=2)$ and were only observed in areas with ABOM.

\section{DISCUSSION}

The excessive accumulation of ABOM on beaches is a secondary effect of inefficient waste management during logging (Putz et al. 2000), and our study is among the first to investigate the resultant impacts on sea turtles. We integrated field surveys with simple field experiments, which have afforded several insights into the 4 main aspects of this emerging conservation issue, as follows.

Firstly, one of the direct effects of the accumulation of organic debris on beaches is an increase in the proportion of clutches laid near the sea, with the subsequent negative effect on their survival due to erosion or flooding (Whitmore \& Dutton 1985, Eckert 
1987, Bell et al. 2004, Patino-Martinez et al. 2014). The presence of beach debris makes it much harder for females to travel as far from the tideline as they would on beaches with no $A B O M$, probably due to either a simple physical barrier effect or potentially through an aversive effect caused by contact with woody material replicating the stimuli received when nesting in a vegetated area (Hirth 1980, Nordmoe et al. 2004).

Secondly, in areas affected by ABOM, turtles spent more time camouflaging their nests. Any situation that forces them to spend more time on land represents an increase in expended energy which may reduce probability of future nesting attempts or the magnitude and quality of investment in eggs or hatchlings (Qualls \& Shine 1998). Additionally, the more time spent by females in exposed situations on a beach, the greater the risk of predation by both wild and feral animals and humans (Fretey et al. 2007, Heithaus et al. 2008) and a greater risk of desiccation or overheating if they remain till dawn. Increased activity increases the risk of injury from direct contact with ABOM. We observed bloody wounds of variable sizes, located on flippers, shoulders, carapace and eyes, caused by interactions between adult females with waste accumulated on beaches, which can be lethal under some conditions (Laurance et al. 2008), though not in our study. This disparity is probably due to the size of waste fragments, which were smaller in our case than in Gabon (Pikesley et al. 2013). However, considering that a given female can nest up to 11 times within a nesting season, the impacts of wounding could be cumulative.

Thirdly, data generated by capture-recapture models suggest that in seasons with large amounts of $\mathrm{ABOM}$, females probably choose to reduce the number of subsequent visits to the affected beaches and disperse over a greater number of adjacent beaches. Within-season movements among rookeries in this species are not unprecedented (Horrocks et al. 2016) but if augmented by $\mathrm{ABOM}$, they could reduce the efficacy of, for example, marine protected areas established around core nesting areas subject to protection (Revuelta et al. 2015). This strategy may increase the survival possibilities of some of the best situated nests and the energy costs for females (Qualls \& Shine 1998). Nevertheless, despite the evidence provided by the different recapture rates among years and the differing levels of ABOM each year, the number of study seasons should be increased to encompass years with different levels of ABOM to compare results obtained over a longer time span.
Fourthly, although preliminary, it appears that $\mathrm{ABOM}$ at this site could represent lethal obstacles for offspring in many cases. Hatchlings are much more vulnerable to waste than their mothers are. They invest at least between 25 and $64 \%$ more time in reaching the sea in areas with intermediate debris, substantially increasing the risk of predation and dehydration (Bourgeois et al. 2009). The additional energetic cost that reaching the sea at beaches with waste represents for the offspring can influence survival opportunities during the first hours of swimming and could lead to a strong reduction in hatchling recruitment to the population. For obvious ethical reasons, experimental quantification of the effect of excessive accumulation of $\mathrm{ABOM}$ on nests and hatchling pathways to the sea was not carried out. However, we observed cases where all hatchlings from nests located in areas with large amounts of $\mathrm{ABOM}$ were unable to overcome large barriers and were easily subject to predation by birds and domestic dogs (J. Patino-Martinez pers. obs.).

\section{CONCLUSION AND MANAGEMENT IMPLICATIONS}

Our study reveals the linkage between terrestrial and marine ecosystem impacts with the resultant decline in sea turtle reproductive success. Although $\mathrm{ABOM}$ does not affect nesting rates, it does bring about an increase in the number of nests laid in close proximity to the sea, with a subsequent negative effect on their survival. Time invested in the nest camouflaging process significantly increases in the presence of $\mathrm{ABOM}$, entailing a greater energetic cost in addition to causing physical injury. Lastly, ABOM acts as a lethal or sublethal barrier to offspring. Taken together, there is the potential for this relatively novel form of anthropogenic pollution to have population-level impacts at affected sites.

Where present, ABOM should be regarded as having an important potential impact on nesting beaches, with the potential to augment the effect of growing amounts of plastic debris (Vegter et al. 2014, Nelms et al. 2015); therefore, beach clean-up should be incorporated into management plans. Repositioning organic waste towards the distant vegetation zone or salvaging it as an energy source may be effective management measures. Care should be taken to ensure that hawksbill turtles, many which nest in the vegetated zones of the same sites as leatherback turtles, are not impacted. At the same time, it is paramount to implement reduced-impact logging practices (Putz et al. 2008, Meyfroidt \& Lambin 2011). 
Acknowledgements. We thank all researchers in Playona and Acandí (GILA team) for their continuing efforts to collect important data. Funding from the Darien Foundation facilitated the monitoring activities. We also thank the local environmental authority in Colombia (CODECHOCO and Consejo Mayor de Comunidades Negras Acandí). The Environmental Office of the Junta de Andalucía (Spain) and Fundación BBVA provided economical support. B.J.G. is supported by the Darwin Initiative.

\section{LITERATURE CITED}

Ackerman RA (1980) Physiological and ecological aspects of gas-exchange by sea turtle eggs. Am Zool 20:575-583

Anderson DR, Burnham KP, White GC (1994) AIC model selection in overdispersed capture-recapture data. Ecology 75:1780-1793

Antworth RL, Pike DA, Stiner JC (2006) Nesting ecology, current status, and conservation of sea turtles on an uninhabited beach in Florida, USA. Biol Conserv 130:10-15

* Bell BA, Spotila JR, Paladino FV, Reina RD (2004) Low reproductive success of leatherback turtles, Dermochelys coriacea, is due to high embryonic mortality. Biol Conserv 115:131-138

Bilinski JJ, Reina RD, Spotila JR, Paladino FV (2001) The effects of nest environment on calcium mobilization by leatherback turtle embryos (Dermochelys coriacea) during development. Comp Biochem Physiol A Mol Integr Physiol 130:151-162

Bourgeois S, Gilot-Fromont E, Viallefont A, Boussamba F, Deem SL (2009) Influence of artificial lights, logs and erosion on leatherback sea turtle hatchling orientation at Pongara National Park, Gabon. Biol Conserv 142:85-93

Brost B, Witherington B, Meylan A, Leone E, Ehrhart L, Bagley D (2015) Sea turtle hatchling production from Florida (USA) beaches, 2002-2012, with recommendations for analyzing hatching success. Endang Species Res 27:53-68

Burnham KP, Anderson DR, White GC, Brownie C, Pollock KH (eds) (1987) Design and analysis methods for fish survival experiments based on release-recapture. American Fisheries Society, Bethesda, MD

Chacón-Chaverri D (1999) Dermochelys coriacea (Testudines: Dermochelyidae) nesting in Playa Gandoca, Costa Rica (1990 through 1997). Rev Biol Trop 47: 225-236

Cooch E, White GC (2004) Program mark: a gentle introduction, 3rd edn. Available at www.phidot.org/software/ mark/docs/book/

Eckert KL (1987) Environmental unpredictability and leatherback sea-turtle (Dermochelys coriacea) nest loss. Herpetologica 43:315-323

Engeman RM, Martin RE, Constantin B, Noel R, Woolard J (2003) Monitoring predators to optimize their management for marine turtle nest protection. Biol Conserv 113: $171-178$

Engeman RM, Martin RE, Smith HT, Woolard J and others (2005) Dramatic reduction in predation on marine turtle nests through improved predator monitoring and management. Oryx 39:318-326

Foley JA, Asner GP, Costa MH, Coe MT and others (2007) Amazonia revealed: forest degradation and loss of ecosystem goods and services in the Amazon Basin. Front Ecol Environ 5:25-32
Fretey J, Billes A, Tiwari M (2007) Leatherback, Dermochelys coriacea, nesting along the Atlantic coast of Africa. Chelonian Conserv Biol 6:126-129

* Glen F, Broderick AC, Godley BJ, Hays GC (2005) Patterns in the emergence of green (Chelonia mydas) and loggerhead (Caretta caretta) turtle hatchlings from their nests. Mar Biol 146:1039-1049

Godfrey $\mathrm{MH}$, Barreto R (1995) Beach vegetation and seafinding orientation of turtle hatchlings. Biol Conserv 74:29-32

Godley BJ, Broderick AC, Glen F, Hays GC (2002) Temperature-dependent sex determination of Ascension Island green turtles. Mar Ecol Prog Ser 226:115-124

Hays GC, Speakman JR (1993) Nest placement by loggerhead turtles, Caretta caretta. Anim Behav 45:47-53

*Heithaus MR, Wirsing AJ, Thomson JA, Burkholder DA (2008) A review of lethal and non-lethal effects of predators on adult marine turtles. J Exp Mar Biol Ecol 356:43-51

Hernandez R, Buitrago J, Guada H, Hernandez-Hamon $\mathrm{H}$, Llano M (2007) Nesting distribution and hatching success of the leatherback, Dermochelys coriacea, in relation to human pressures at Playa Parguito, Magarita Island, Venezuela. Chelonian Conserv Biol 6:79-86

*Hilterman ML, Goverse E (2007) Nesting and nest success of the leatherback turtle (Dermochelys coriacea) in Suriname, 1999-2005. Chelonian Conserv Biol 6:87-100

*Hirth H (1980) Some aspects of the nesting behaviour and reproductive biology of sea turtles. Am Zool 20:507-523

* Horrocks JA, Stapleton S, Guada H, Lloyd C and others (2016) International movements of adult female leatherback turtles in the Caribbean: results from tag recovery data (2002-2013). Endang Species Res 29:279-287

*Houghton JDR, Myers AE, Lloyd C, King RS, Isaacs C, Hays GC (2007) Protracted rainfall decreases temperature within leatherback turtle (Dermochelys coriacea) clutches in Grenada, West Indies: ecological implications for a species displaying temperature dependent sex determination. J Exp Mar Biol Ecol 345:71-77

Howard R, Bell I, Pike DA (2014) Thermal tolerances of sea turtle embryos: current understanding and future directions. Endang Spec Res 26:75-86

Kamel SJ, Mrosovsky N (2004) Nest site selection in leatherbacks, Dermochelys coriacea: individual patterns and their consequences. Anim Behav 68:357-366

* Laurance WF, Fay JM, Parnell RJ, Sounguet GP, Formia A, Lee ME (2008) Does rainforest logging threaten marine turtles? Oryx 42:246-251

K Lolavar A, Wyneken J (2015) Effect of rainfall on loggerhead turtle nest temperatures, sand temperatures and hatchling sex. Endang Species Res 28:235-247

Marco A, Abella-Perez E, Tiwari M (2017) Vulnerability of loggerhead turtle eggs to the presence of clay and silt on nesting beaches. J Exp Mar Biol Ecol 486:195-203

Maros A, Louveaux A, Liot E, Marmet J, Girondot M (2005) Identifying characteristics of Scapteriscus spp. (Orthoptera: Gryllotalpidae) apparent predators of marine turtle eggs. Environ Entomol 34:1063-1070

* Matsuzawa Y, Sato K, Sakamoto W, Bjorndal KA (2002) Seasonal fluctuations in sand temperature: effects on the incubation period and mortality of loggerhead sea turtle (Caretta caretta) pre-emergent hatchlings in Minabe, Japan. Mar Biol 140:639-646

Meyfroidt P, Lambin EF (2011) Global forest transition: prospects for an end to deforestation. Annu Rev Environ Resour 36:343-371 
Mortimer JA (1990) The influence of beach sand characteristics on the nesting-behavior and clutch survival of green turtles (Chelonia mydas). Copeia 1990:802-817

Nelms SE, Duncan EM, Broderick AC, Galloway TS and others (2015) Plastic and marine turtles: a review and call for research. ICES J Mar Sci 73:165-181

Nordmoe ED, Sieg AE, Sotherland PR, Spotila JR, Paladino FV, Reina RD (2004) Nest site fidelity of leatherback turtles at Playa Grande, Costa Rica. Anim Behav 68:387-394

Patino-Martinez J, Marco A, Quinones L, Godley B (2008) Globally significant nesting of the leatherback turtle (Dermochelys coriacea) on the Caribbean coast of Colombia and Panama. Biol Conserv 141:1982-1988

*Patino-Martinez J, Marco A, Quiñones L, Abella E, Abad RM, Dieguez-Uribeondo J (2012a) How do hatcheries influence embryonic development of sea turtle eggs? Experimental analysis and isolation of microorganisms in leatherback turtle eggs. J Exp Zool A Ecol Genet Physiol 317:47-54

Patino-Martinez J, Marco A, Quinones L, Hawkes L (2012b) A potential tool to mitigate the impacts of climate change to the Caribbean leatherback sea turtle. Glob Change Biol 18:401-411

Patino-Martinez J, Marco A, Quiñones L, Hawkes L (2014) The potential future influence of sea level rise on leatherback turtle nests. J Exp Mar Biol Ecol 461:116-123

Phillott AD, Elsmore SAM (2004) Black noddies (Anous minutus) and wedge-tailed shearwaters (Puffinis pacificus) as potential hosts for fungi invading sea turtle nests at Heron Island, Queensland. Trans R Soc S Aust 128:73-76

Phillott AD, Parmenter CJ, Limpus CJ, Harrower KM (2002) Mycobiota as acute and chronic cloacal contaminants of female sea turtles. Aust J Zool 50:687-695

Pike DA, Stiner JC (2007) Fluctuating reproductive output and environmental stochasticity: Do years with more reproducing females result in more offspring? Can J Zool 85:737-742

Pikesley SK, Agamboue PD, Bonguno EA, Boussamba F and others (2013) Here today, here tomorrow: beached timber in Gabon, a persistent threat to nesting sea turtles. Biol Conserv 162:127-132

Putz FE, Dykstra DP, Heinrich R (2000) Why poor logging practices persist in the tropics. Conserv Biol 14:951-956

Putz F, Sist P, Fredericksen T, Dykstra D (2008) Reducedimpact logging: challenges and opportunities. For Ecol Manag 256:1427-1433

Qualls CP, Shine R (1998) Costs of reproduction in conspecific oviparous and viviparous lizards, Lerista bougainvillii. Oikos 82:539-551

Reece SE, Broderick AC, Godley BJ, West SA (2002) The effects of incubation environment, sex and pedigree on the hatchling phenotype in a natural population of loggerhead turtles. Evol Ecol Res 4:737-748
Reising M, Salmon M, Stapleton S (2015) Hawksbill nest site selection affects hatchling survival at a rookery in Antigua, West Indies. Endang Species Res 29:179-187

* Revuelta O, Hawkes L, León YM, Godley BJ, Raga JA, Tomás J (2015) Evaluating the importance of Marine Protected Areas for the conservation of hawksbill turtles Eretmochelys imbricata nesting in the Dominican Republic. Endang Species Res 27:169-180

Rivalan P, Godfrey MH, Prévot-Julliard AC, Girondot M (2005) Maximum likelihood estimates of tag loss in leatherback sea turtles. J Wildl Manag 69:540-548

* Rivas ML, Marco A (2016) The effect of dune vegetation on leatherback hatchling's sea-finding ability. Mar Biol 163:13

Rivas ML, Santidrián Tomillo P, Diéguez-Uribeondo J, Marco A (2016) Potential effects of dune scarps caused by beach erosion on the nesting behavior of leatherback turtles. Mar Ecol Prog Ser 551:239-248

Salmon M, Witherington BE (1995) Artificial lighting and seafinding by loggerhead hatchlings: evidence for lunar modulation. Copeia 1995:931-938

* Salmon M, Wyneken J, Fritz E, Lucas M (1992) Seafinding by hatchling sea-turtles - role of brightness, silhouette and beach slope as orientation cues. Behaviour 122: 56-77

Sarmiento-Ramírez JM, Abella-Pérez E, Phillott AD, Sim J and others (2014) Global distribution of two fungal pathogens threatening endangered sea turtles. PLOS ONE 9:e85853

Thiel M, Gutow L (2005) The ecology of rafting in the marine environment - I - the floating substrata. Oceanogr Marine Biol Annu Rev 42:181-263

*Vegter AC, Barletta M, Beck C, Borrero J and others (2014) Global research priorities to mitigate plastic pollution impacts on marine wildlife. Endang Species Res 25: 225-247

*Velander K, Mocogni M (1999) Beach litter sampling strategies: Is there a 'best' method? Mar Pollut Bull 38: 1134-1140

*Wallace BP, Sotherland PR, Spotila JR, Reina RD, Franks BF, Paladino FV (2004) Biotic and abiotic factors affect the nest environment of embryonic leatherback turtles, Dermochelys coriacea. Physiol Biochem Zool 77: $423-432$

* Whitmore CP, Dutton PH (1985) Infertility, embryonic mortality and nest-site selection in leatherback and green sea turtles in Suriname. Biol Conserv 34:251-272

*Wood DW, Bjorndal KA (2000) Relation of temperature, moisture, salinity, and slope to nest site selection in loggerhead sea turtles. Copeia 2000:119-128

Wyneken J, Salmon M (1992) Frenzy and postfrenzy swimming activity in loggerhead, green and leatherback hatchling sea turtles. Copeia 1992:478-484 


\section{Appendix 1}

Table A1. Models of the survival and recapture rates of breeding female leatherback turtles Dermochelys coriacea in 2005-2007. Capture-recapture data were gathered at La Playona (3 km, NE Colombia). Session: parameters may change between capture sessions. ABOM: parameters may change between study years (year with no accumulated beach organic material $[\mathrm{ABOM}]$, year with abundant $\mathrm{ABOM}$ or year with intermediate levels of ABOM). +: sum of the principal factors; $\times$ : interaction of the principal factors; Np: number of parameters; Phi: survival rate; P: recapture rate; QAIC ${ }_{\mathrm{c}}$ : quasi-likelihood Akaike's information criterion. The model highlighted in bold was considered the best model

\begin{tabular}{|lccc|}
\hline Model & QAIC $_{\mathrm{c}}$ & Np & Deviance \\
\hline Phi(session) P(ABOM) & $\mathbf{1 2 2 5 . 5}$ & $\mathbf{9}$ & $\mathbf{1 9 3 . 5}$ \\
Phi(ABOM+session) P(ABOM) & 1228.6 & 11 & 192.5 \\
Phi(ABOM+session+ABOM×session) P(ABOM) & 1238.6 & 21 & 181.4 \\
Phi(ABOM+session+ABOM×session) P(ABOM+session) & 1243.3 & 26 & 175.2 \\
Phi(ABOM+session+ABOM×session) P(constant) & 1250.5 & 19 & 197.5 \\
Phi(ABOM+session+ABOM×session) P(session) & 1254.3 & 24 & 190.6 \\
Phi(ABOM+session+ABOM×session) P(ABOM+session+ABOM×session) & 1258.6 & 36 & 168.2 \\
Phi(constant) P(ABOM) & 1285.5 & 4 & 263.8 \\
Phi(ABOM) P(ABOM) & 1287.8 & 6 & 262.0 \\
\hline
\end{tabular}

Editorial responsibility: Graeme Hays, Burwood, Victoria, Australia
Submitted: December 18, 2015; Accepted: January 23, 2017 Proofs received from author(s): March 15, 2017 